\title{
Psychometric Properties of the Self-Assessment of the Interpersonal Relationship Scale
}

\author{
Karen S. Dearing \\ Sheryl Steadman
}

Follow this and additional works at: https://scholarsarchive.byu.edu/facpub

Part of the Nursing Commons

\section{Original Publication Citation}

K. S. Dearing, S. Steadman, (29). Psychometric Properties of the Self-Assessment of the Interpersonal Relationship Scale.

\section{BYU ScholarsArchive Citation}

Dearing, Karen S. and Steadman, Sheryl, "Psychometric Properties of the Self-Assessment of the Interpersonal Relationship Scale" (2009). Faculty Publications. 48.

https://scholarsarchive.byu.edu/facpub/48

This Poster is brought to you for free and open access by BYU ScholarsArchive. It has been accepted for inclusion in Faculty Publications by an authorized administrator of BYU ScholarsArchive. For more information, please contact ellen_amatangelo@byu.edu. 


\section{BYU College of Nursing} nursing.byu.edu
Psychometric Properties of the Self-Assessment of the Interpersonal Relationship Scale

Karen S. Dearing, PhD, APRN, Brigham Young University; Sheryl Steadman, PhD, APRN, Westminster College

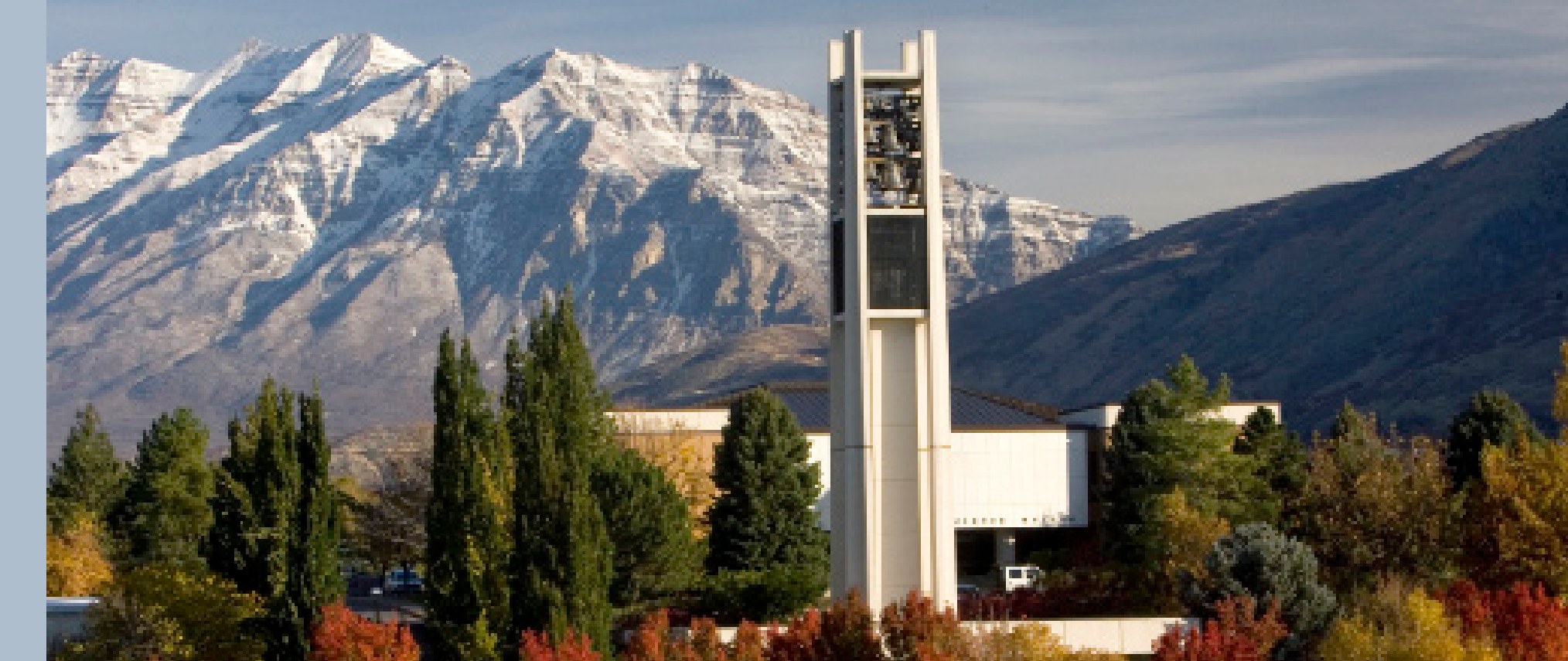

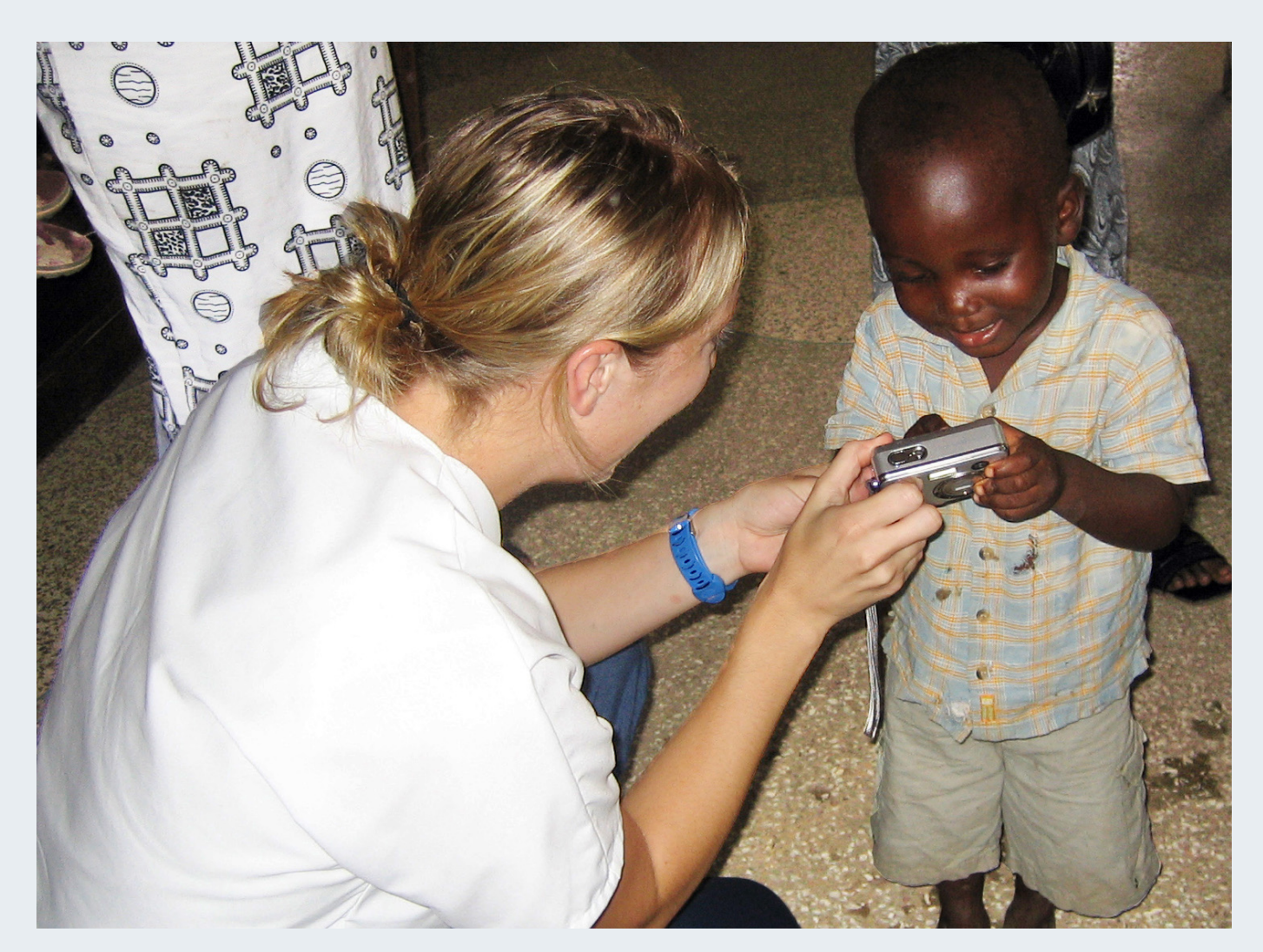

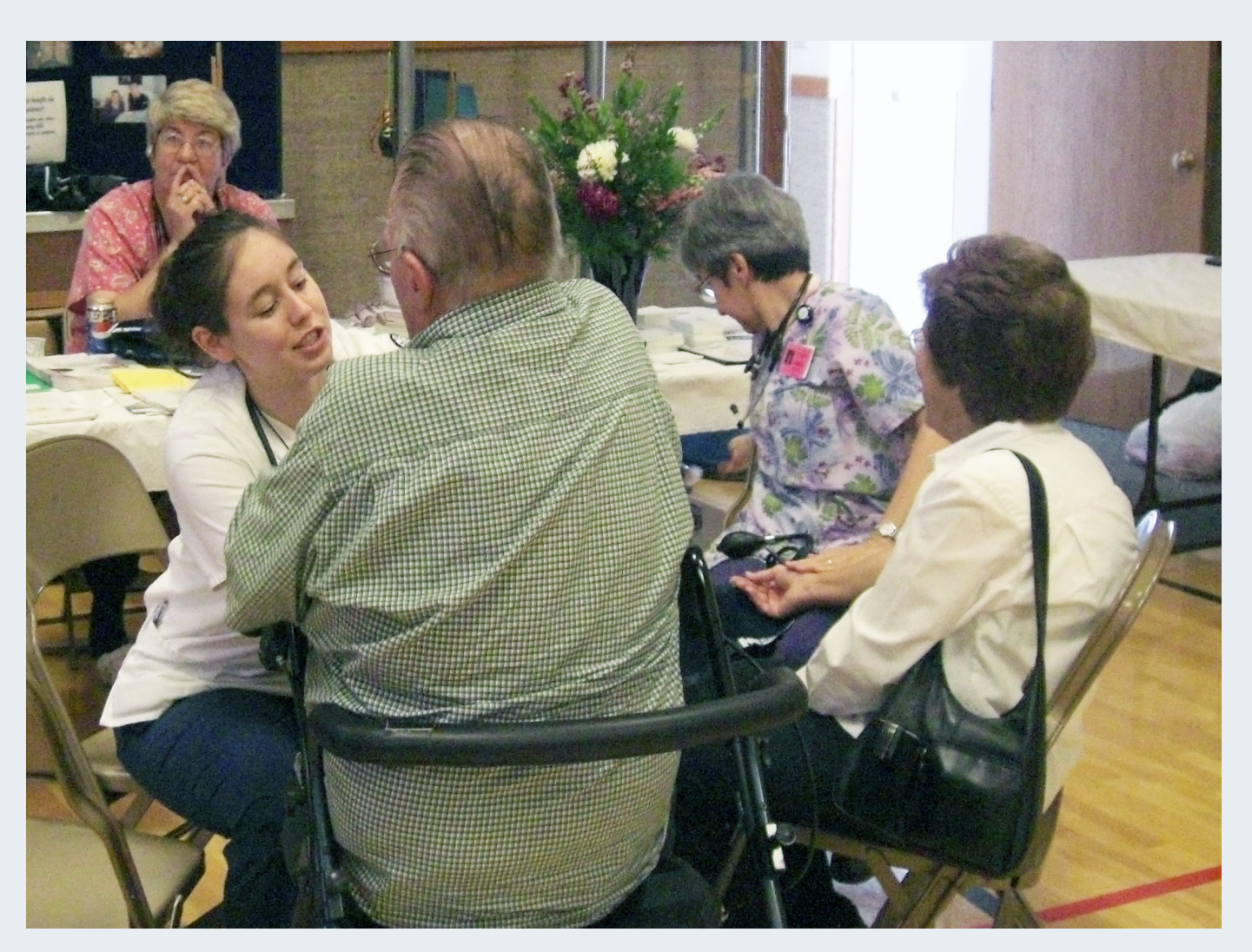

\section{Background}

-The nurse-patient relationship is the basis of psychiatric nursing.

- The use of self defines nursing as an interactive exploratory, caring, and health promoting process.

- No tool has been developed to determine specific areas for competency building using the principles of developing an interpersonal relationship.

\section{Purpose}

- The specific aims of the study were two-fold:

- Establish the reliability and validity of the SelfAssessment of the Interpersonal Relationship Scale (SAIRS)

- Determine the ability of SAIRS to measure student nurses development of interpersonal competencies with patients

\section{Methods/Instrument Development}

- Scale Development - The items were developed based on Peplua's interpersonal theory and extensive literature review completed in 2003 and piloted in 2004.

- Face Validity - A team of five experts refined the scale by removing constructs not related, as identified through statistical evaluation of pilot study.

- Measures - Each item statement on the scale delineates areas of strengths and areas for personal growth (SA-strongly agree, A-agree, NS-not sure, D-disagree, SD-strongly disagree)

- Sample - 248 subjects enrolled in the study were English speaking men and women between the ages of 18-55.

\section{Data Analysis/Results}

- SPSS version $14-$ statistical significance set at $p=<0.05$

- Factor Analysis - the interpersonal relationship and competencies

- Subscales identified

- receptive

- core

- complimentary

- Chronbach's Alpha - .8989

- Split-half Reliability - .9167

- Interclass Correlation Coefficient

- $F$ value $=14.79$

- $p=.0000$

$\bullet \mathrm{Cl}=.91-.94$

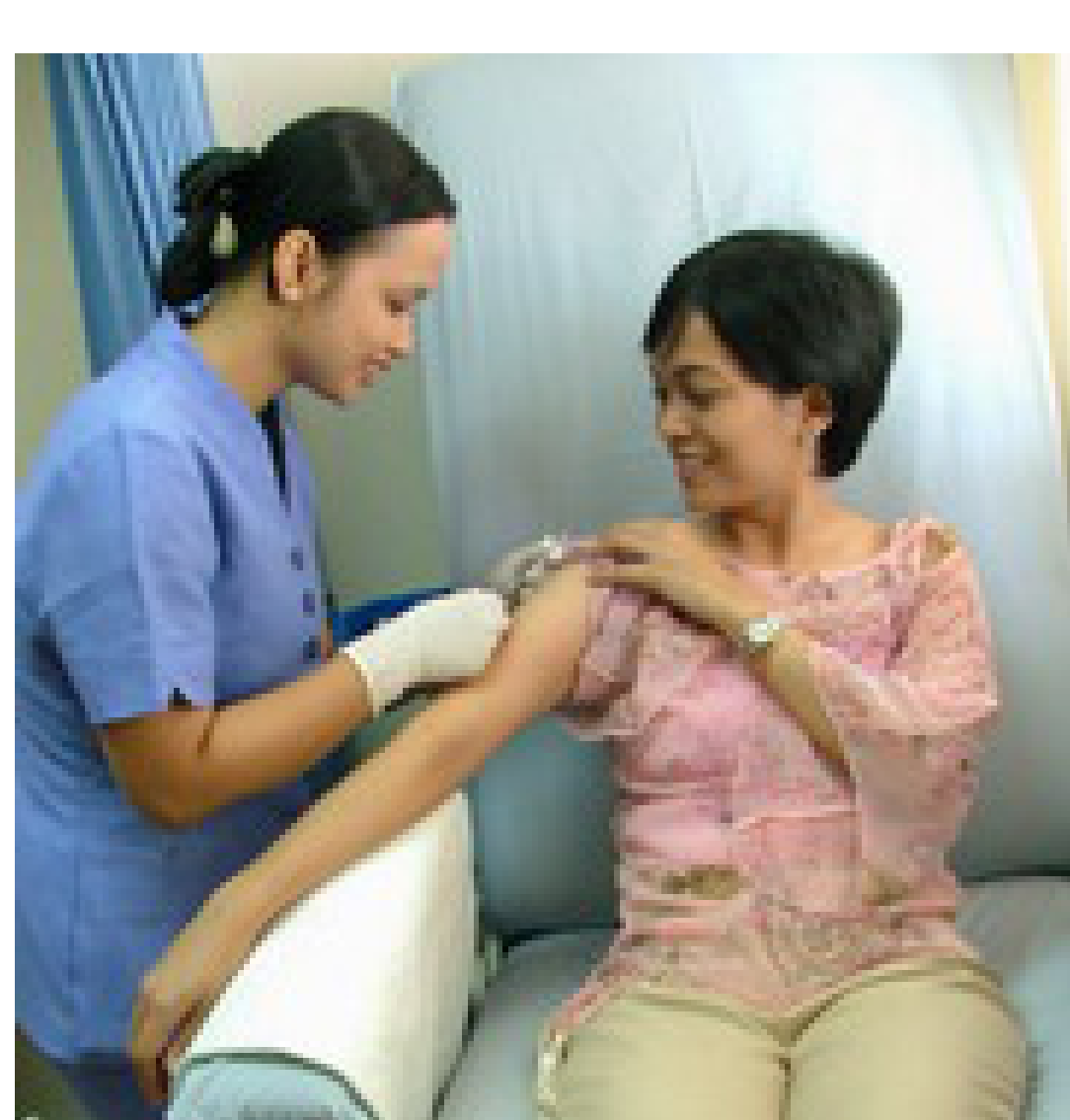

\section{Discussion}

- High level of association within the total scale and subscales

- Interclass correlation coefficient identifies questions are tightly correlated

- Competency subscales categorize:

- Competencies necessary to engage in the interpersonal process

- Competencies related to facilitate the interpersona process

- Competencies which establish a true bond through the nurse-patient interpersonal process

\section{References}

Dearing, K. S., (2004). Getting it, together: How the nurse/patien relationship influences treatment compliance for patients with schizophrenia. Archives of Psychiatric Nursing, 18(5), 155-63. Lego, S., (1999). The one-to-one nurse/patient relationship. Perspectives Psychiatric Care, 35,(4), 4-23.

Orlando I. J. (1990). The dynamic nurse/patient relationship. (Publication No.15-2341). New York: National League for Nursing

Peplau, H. E., (1952). Interpersonal Relations in Nursing. New York: G.P. Putnam's Sons.

\section{Subscales}

\section{Receptive Traits:}

Honest/sincere

Respect uniqueness

Focus on client issues

Convey worth

Communicate understanding

Convey empathy

Listen to client perspective

\section{Core Traits:}

Help with problem solving

Questions facilitate communication

Recognize ineffective responses

Achieve goals

Help client meet goals

Establish achievable goals

Understand client reaction

Change to respond more effectively

Accept powerful emotion

Gather data

Identify stren

trength/weakness

Consistently maintain boundaries

S.D.

.54

60

Complimentary Traits:

Relationship therapeutic/not socia

Discuss incongruence

Help acknowledge progress

.81

Available as resource

Do not use IPR to solve problem

Help patient with unmet goals

Free of bias

Determine long/short term goals

Discuss termination openly

Explain roles

Self-disclose appropriately

.66
.67
.69
.69
.70
.70
.71
.71
.72
.72
.74
.75

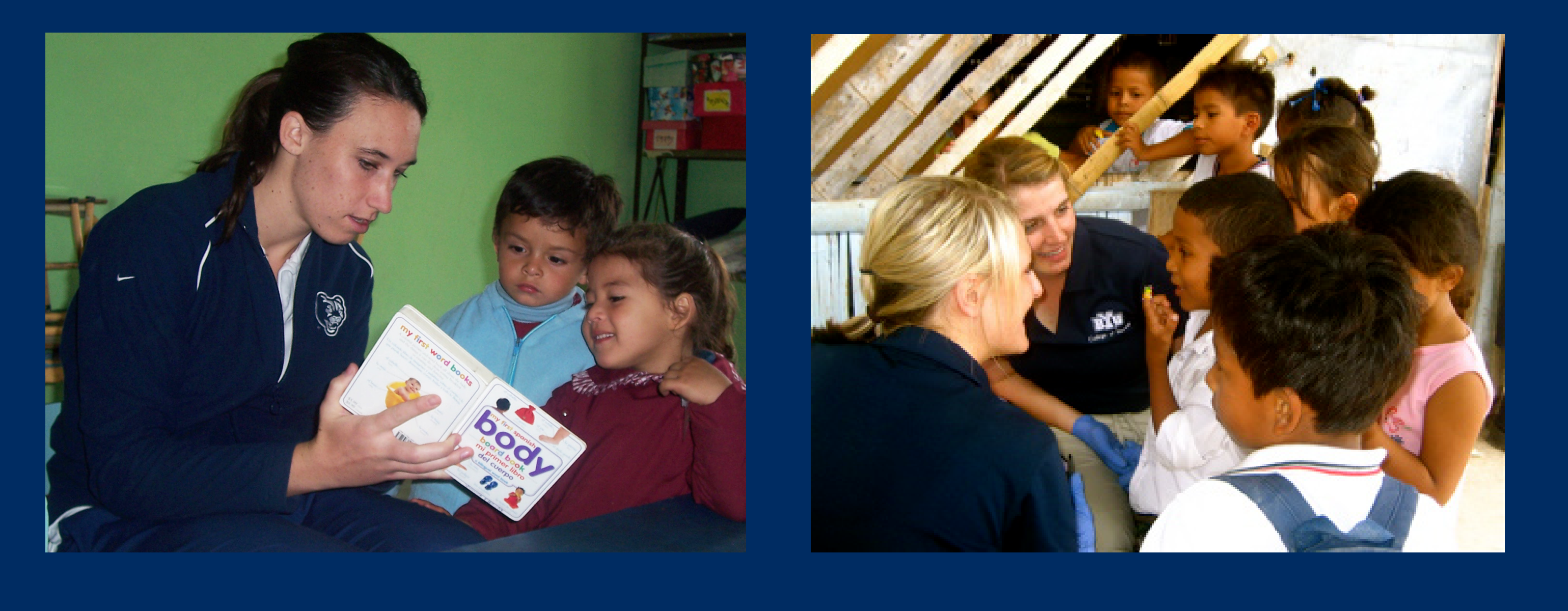

